\title{
MANIFESTAÇÕES CLÍNICAS EM GATOS COM HIPERTIREOIDISMO EXPERIMENTAL*
}

\author{
(Clinical changes in cats submitted to experimental hyperthyroidism)
}

\author{
CARDOSO, M.J.L.'; COSTA, F.S. ${ }^{2}$; MUNIZ, L.M.R. ${ }^{3}$; ZALITH, A.C.A. ${ }^{4}$; \\ PADOVANI, C.R.5 ${ }^{5}$; ARAGON, F.F. ${ }^{5}$
}

\begin{abstract}
${ }^{1}$ Prof de Clínica Médica e Semiologia de Pequenos Animais - FFALM - Bandeirantes - PR e Doutorando FMVZ - UNESP - Botucatu - SP. Endereço para Correspondência: Hospital Veterinário - FFALM - UNESPAR - BR 369, Km 54, Cx. Postal 261 - 86360-000. Bandeirantes - PR;

${ }^{2}$ Prof. de Diagnóstico por Imagem - UFES - Alegre - ES e Doutorando - FMVZ - UNESP - Botucatu - SP; ${ }^{3}$ Profa. de Radiologia do Depto de Reprodução Animal e Radiologia Veterinária - FMVZ - UNESP - Botucatu - SP; ${ }^{4}$ Médica Veterinária, Doutoranda - FMVZ - UNESP - Botucatu - SP; ${ }^{5}$ Depto de Bioestatística - IB - UNESP - Botucatu - SP.
\end{abstract}

RESUMO - A relação do hipertireoidismo experimental com parâmetros clínicos foi avaliada em gatos machos e fêmeas, intactos e mantidos em estado hipertireóideo por um período de 42 dias. Os parâmetros estudados foram consumo diário de água e ração, débito urinário, o volume fecal, peso corporal, temperatura corporal, coloração de membranas mucosas, palpação de linfonodos superficiais, palpação da glândula tireóide, pulso femoral, auscultação cardíaca e respiratória, freqüência cardíaca e respiratória e palpação abdominal. Correlacionou-se as variáveis com os níveis de T3 total, T4 livre e total. O excesso dos hormônios tireoidianos acompanhou aumento da freqüência cardíaca, polifagia, polidipsia, perda de peso e aumento do volume fecal nos gatos estudados.

Palavras-chave: gatos, tireóide, manifestações clínicas, hipertireoidismo, T3, T4.

SUMMARY - The interrelation between experimental hyperthyroidism andclinical changes was studied in adult intact cats kept under hyperthyroidic state for 42 days. Clinical aspects evaluated were dairy food and water intake, urine output and fecal volume, body weight, temperature, mucous membranes colour, palpable lymphnodes, thyroid gland palpation, abdominal palpation, and cardiac and respiratory frequencies. These characteristics were correlated with free and total T4 and total T3 serum concentrations. Excessive circulant thyroid hormone levels resulted in increased cardiac frequency, polyuria, polidipsia, weight loss and increased fecal volume in the studied cats.

Key-words: cats, thyroid, clinical changes, hyperthyroidism, T3, T4.

\section{Introdução e Revisão de Literatura}

O hipertireoidismo é uma alteração clínica multissistêmica resultante de excessivas concentrações dos hormônios tireoidianos (tiroxina - T4 e triiodotironina - T3) e é tido como a doença endócrina mais comum em gatos domésticos (MOONEY et al., 1996a).

O hipertireoidismo é uma doença que ocorre principalmente em gatos de meia-idade a idosos, não havendo prevalência quanto ao sexo (PETERSON et al., 1983; THODAY e MOONEY, 1992). As manifestações clínicas evoluem lentamente podendo ser de leves a graves, dependendo do estágio da doença e da coexistência de outras alterações sistêmicas.

Os gatos hipertireóideos inicialmente são ativos/hiperativos com apetite normal, podendo com a progressão da doença apresentar perda 
de peso, polifagia, vômito, poliúria, polidipsia e hiperatividade (PETERSON et al., 1983; THODAY e MOONEY, 1992; BROUSSARD et al., 1995; PETERSON, 1997). As alterações renais são freqüentes, mas a sua patogenia ainda não está completamente elucidada. A gravidade dos sinais renais relaciona-se com a existência ou não de insuficiência renal primária, pois os gatos acometidos de hipertireoidismo espontâneo são geralmente de meia-idade a idosos e é sabido que gatos velhos tem freqüentemente insuficiência renal crônica (DIBARTOLA e BROWN, 2000).

A poliúria e a polidipsia são sinais clínicos relativamente freqüentes entre gatos hipertireóideos, embora a doença renal primária concomitante possa contribuir (PETERSON, 2004). A causa da poliúria e da polidipsia no hipertireoidismo é desconhecida, mas o excesso dos hormônios tireoidianos prejudica a concentração urinária devido ao aumento do fluxo sangüíneo renal, da taxa de filtração glomerular e da capacidade de secreção e reabsorção em ratos e no homem (ADAMS et al., 1997). Outra hipótese é a tireotoxicose provocar alteração no hipotálamo e esta polidipsia compulsória e secundariamente à poliúria (PETERSON, 2004). Ambas hipóteses necessitam de comprovação.

No exame físico, as alterações mais observadas são glândula tireóide aumentada de volume, emagrecimento e hipertermia. Observase também sopros sistólicos, taquicardia, ritmo de galope, além de outras arritmias cardíacas. A progressão da doença cardíaca pode resultar em insuficiência cardíaca congestiva, dispnéia, sons cardíacos abafados e ascite (PETERSON et al., 1983; THODAY e MOONEY, 1992; PETERSON, 1997). A patogenia das alterações cardíacas são desconhecidas e provavelmente são compensatórias às alterações teciduais periféricas (PETERSON, 2004). Sabe-se que o excesso dos hormônios tiroidianos provoca hipertrofia ventricular esquerda, aumento na contratilidade e na freqüência cardíaca (KLEIN, 1990; POLIKAR et al. 1993). Os felinos com hipertireoidismo apresentam miocardiopatia hipertrófica e menos comumente a miocardiopatia dilatada e, ambas, podem causar insuficiência cardíaca congestiva. O excesso dos hormônios tireoidianos induzem a produção de uma isoforma de miosina que aumenta a velocidade da interação miosina-actina, o aumento da atividade da $\mathrm{Ca}^{+}$-ATPase no retículo sarcoplasmático e aumento dos canais de cálcio; todos estes eventos contribuem para o aumento da contratilidade. No hipertiroidismo também há aumento do número de receptores betaadrenérgicos que influenciam no acréscimo da contratilidade e no desenvolvimento da hipertrofia cardíaca (PANCIERA, 2000).

Os sinais respiratórios mais comuns no hipertireoidismo felino são dispnéia, respiração ofegante e hiperventilação (BROUSSARD et al., 1995). Estes sinais normalmente estão relacionados com o estresse do transporte do animal e pelo exame físico (PETERSON, 2004). A insuficiência cardíaca congestiva (ICC) tireotóxica também pode contribuir para estas alterações respiratórias (LIU et al., 1984). Os gatos podem apresentar ainda pelagem seca, sem brilho, com áreas alopécicas, astenia e fraqueza muscular, intranqüilidade, ansiedade, agressividade e intolerância a situações de estresse (PETERSON et al., 1983; THODAY e MOONEY, 1992; BROUSSARD et al., 1995).

As concentrações séricas da T3 total (TT3), T3 livre (FT3), T4 total (TT4) e T4 livre (LT4) elevadas são os principais indicativos de hipertireoidismo felino, na maioria dos casos (PETERSON et al., 1983; PETERSON, 1984; THODAY e MOONEY, 1992; MOONEY et al., 1996a; PETERSON et al., 2001). BROUSSARD et al. (1995) relataram que aproximadamente $25 \%$ dos gatos com hipertireoidismo apresentaram a concentração de T3 normal e a de T4 elevada, isso mostra a importância que o hormônio tem para o auxílio diagnóstico (PETERSON, 1997). De 2 a 10\% dos gatos hipertireóideos podem apresentar concentrações de T3 e T4 dentro dos valores normais (MCLOUGHLIN et al., 1993; BROUSSARD et al., 1995). As concentrações séricas normais para os hormônios tireoidianos em gatos com hipertireoidismo podem ser devidas às flutuações de T3 e T4 "entrando e saindo" da faixa de normalidade; ou ainda ser resultante de enfermidades não tireoidianas concomitantes (PETERSON et al., 1987; PETERSON e GAMBLE, 1990; THODAY e MOONEY, 1992; MCLOUGHLIN et al., 1993; MOONEY et al., 1996b; PETERSON, 1997).

Valores de TT4 dentro dos valores de 
referência para gatos normais também pode ocorrer em gatos com hipertireoidismo, achado este descrito em 3\% (PETERSON et al., 1983), em 9\% (THODAY e MOONEY, 1992) e em $29 \%$ dos casos (BROUSSARD et al. 1995). Em um estudo realizado por PETERSON et al. (2001) com 917 gatos hipertireóideos, a concentração sérica de TT4 estava dentro do padrão de normalidade para a espécie em $33,5 \%$ dos casos. A concentração de TT3 tem aumento, à medida que a tirotoxicose agrava-se, sem tratamento. A ocorrência de doenças não tireoidianas pode promover o decréscimo na concentração da TT3 em virtude da diminuição da conversão periférica do T4 em T3, evento bem determinado em humanos e este fenômeno parece existir em gatos mas é menos freqüente (THODAY e MOONEY, 1992).

Segundo resultados de FERGUSON et al. (1989), todos os gatos com hipertireoidismo apresentaram concentrações de TT4 acima da faixa normal, mas ocorreu alguma superposição das concentrações de LT4 entre gatos normais e hipertireóideos. Estes resultados sugerem que o uso das determinações de FT3 ou LT4 trará poucas vantagens sobre o uso apenas das determinações de TT4 (GRAVES e PETERSON, 1994).

A mensuração de LT4 foi avaliada em gatos hipertireóideos e representa um bom teste diagnóstico, particularmente em gatos com TT4 dentro dos valores de referência. A mensuração da LT4 é mais acurada na avaliação do status da glândula tireóide, quando comparada às concentrações de TT4, pois sofre menos interferência de fatores não tireoidianos. Quando a concentração de TT4 aumenta, há um aumento desproporcional da LT4, pela saturação das proteínas pelo hormônio e pela ligação subnormal com as proteínas. Além disso, a concentração de LT4 permanece elevada nos pacientes que apresentam hipertireoidismo e doença não tiroidiana concomitante (PETERSON et al., 2001).

Em um estudo em gatos hiperiróideos, a concentração da LT4 estava elevada em 98,5\% dos gatos e a TT4 em 91,3\% (PETERSON et al., 2001). O inconveniente da mensuração é que 6$12 \%$ dos gatos eutireóideos possuem a LT4 elevada, portanto a interpretação da LT4 deve ser usada com cautela, quando utilizada isoladamente (PETERSON et al., 2001).

Os valores normais de TT4 variam de 9,7-56,3 $\mathrm{nmol} / \mathrm{L}(0,7-3,8 \mathrm{mg} / \mathrm{dL})$, os de LT4 de $12-51 \mathrm{pmol} /$ $\mathrm{L}(0,93-3,96 \mathrm{ng} / \mathrm{dL})$ e para TT3 de $0,16-1,9 \mathrm{nmol} /$ $\mathrm{L}(10-104 \mathrm{ng} / \mathrm{dL}$ ) conforme diversos autores (PETERSON et al., 2001; 1997; FELDMAN e NELSON, 1996; MOONEY et al., 1996b; REFSAL et al., 1991; LIU et al., 1984; PETERSON et al., 1983; REIMERS et al., 1981). Valores dos hormônios tireoidianos de gatos com hipertireoidismo espontâneo variam de 35,9693,6 nmol/L (2,8-26,8 mg/dL) para a TT4, de 41-144 pmol/L para LT4 e de 0,46-15,4 nmol/L (44-1000 ng/dL) para TT3 (PETERSON et al., 2001, PETERSON et al., 1997, FELDMAN e NELSON, 1996, MOONEY et al., 1996b, REFSAL et al., 1991, MOISE e DIETZE, 1986, LIU et al., 1984, PETERSON et al., 1983).

O objetivo deste trabalho foi induzir a tirotoxicose em gatos normais, durante um período experimental de 42 dias e a partir da elevação nos níveis dos hormônios tireoidianos em gatos sem doenças concomitantes, identificar possíveis alterações clínicas e suas correlações com os níveis dos hormônios tireoidianos.

\section{Materiais e Métodos}

Foram estudados 19 gatos, adultos jovens, sadios, sem raça definida, com média de peso corporal de $3,25 \pm 0,67 \mathrm{~kg}$. Os animais foram alojados em jaulas individuais de ferro esmaltado, alimentados com ração seca comercial ${ }^{1}$ e água a vontade. Os estudos foram iniciados após um período de 15 dias de adaptação dos gatos ao ambiente e manejo. No início deste período os animais foram vacinados contra raiva ${ }^{2}$, panleucopenia felina, rinotraqueíte e calicivirose ${ }^{3}$, receberam vermífugo ${ }^{4}$ e tratamento com antiparasitário tópico ${ }^{5}$.

'WhiskasÒ Frango. Div. Éffem Produtos Alimentícios. Br 116, Km 286, Eldorado do Sul, RS.

${ }^{2}$ DefensorÒ. Pfizer Divisão de Saúde Animal. Guarulhos $-\mathrm{SP}$.

${ }^{3}$ FelocellÒ CVR. Pfizer Divisão de Saúde Animal. Guarulhos - SP.

${ }^{4}$ DrontalÒ Gatos. Bayer S/A do Brasil. São Paulo - SP.

${ }^{5}$ FrontLineÒ. Merial Saúde Animal Ltda. Fazenda São Francisco - Paulínia - SP.

${ }^{6}$ Coat a CountÒ Total $T_{3}$, Diagnostic Products Co., Los Angeles, C.A., USA. 
A tireotoxicose foi induzida pela administração oral, de comprimidos, de levotiroxina sódica $(150 \mathrm{mg} / \mathrm{kg} / \mathrm{dia})$ durante 42 dias. A administração do hormônio foi realizada entre as sete e oito horas da manhã. Semanalmente, os animais que apresentavam diminuição do peso corporal secundário aos efeitos do excesso dos hormônios tireoidianos, as doses de levotiroxina sódica foram recalculadas e ajustadas para a manutenção da dose de $150 \mathrm{mg} / \mathrm{kg} / \mathrm{dia}$.

Os animais foram avaliados em sete momentos (M). O M0, feito antes da administração da levotiroxina sódica, resultou nos valores basais dos diversos parâmetros estudados. Durante o período experimental, cuja duração foi de 42 dias, foram considerados outros seis momentos de avaliação: aos sete dias (M1, aos 14 dias (M2), aos 21 dias (M3), aos 28 dias (M4), aos 35 dias (M5) e aos 42 dias (M6). A coleta de sangue, para obtenção do soro ou do sangue total, foram realizadas quatro horas após a administração da levotiroxina sódica.

Diariamente foi realizado exame físico e observação do comportamento dos gatos e os dados obtidos foram anotados em fichas individuais. Os parâmetros estudados incluíram mensuração do consumo de ração, consumo de água, peso corporal, temperatura retal, coloração das mucosas, palpação de linfonodos superficiais, palpação de região cervical (glândula tireóide), auscultação cardio-respiratória, freqüências cardíaca e respiratória, pulso femoral, palpação abdominal, exame da pele/pêlos e observação do comportamento e da locomoção. Havia um observador durante todo o período com os animais, para fazer as devidas observações e anotações. O volume fecal, postura para defecação, freqüência e volume urinário foram quantificadas pelo observador e anotadas em fichas individuais, o M0 foi parâmetro para as observações.

Em amostras de soro foram dosadas as concentrações de TT3, TT4 e LT4. A dosagem dos níveis séricos de TT3, TT4, LT4 foi determinada pela técnica de radioimunoensaio (RIA) em fase sólida, utilizando-se conjunto de reagente comercial ${ }^{6}$. Semanalmente também realizou-se hemograma, urinálise, perfil bioquímico completo, eletrocardiografia, radiografia torácica, ultrasonografia abdominal e cervical (tireóide).
Para o estudo das variáveis mensuradas em momentos consecutivos foi considerada a análise de medidas repetidas. Quando a variável apresentou adequação à distribuição normal de probabilidade, o procedimento adotado foi o paramétrico, enquanto que, na ausência desta optou-se pelo procedimento não paramétrico. O estudo das associações de algumas variáveis de interesse em relação a TT4 e LT4 foi realizado considerando o coeficiente de correlação linear Spearrman e o nível de significância utilizado foi de 5\%. (STREINER e NORMAN, 1994).

\section{Resultados}

Os resultados dos níveis séricos da TT3, TT4 e da LT4 nos 19 gatos com tirotoxicose experimental em cada momento de observação, estão dispostos na TABELA 1. A tiroxina total e livre apresentaram diferenças significativas entre o momento zero e os demais momentos, os quais não diferiram entre si. A TT3 não apresentou diferença significativa entre os sete momentos.

Nenhum dos 19 gatos apresentou desidratação clínica durante o período experimental. Os parâmetros utilizados para avaliar o grau de hidratação foram turgor da pele, brilho das mucosas, tempo de perfusão capilar, densidade urinária, hemograma e proteína sérica. Todos os gatos apresentaram aumento do volume fecal e na freqüência de defecção durante o período experimental. Três gatos apresentaram diarréia em jatos após a segunda semana da indução da tirotoxicose. O exame coproparasitológico e microscópico foram negativos para presença de parasitas e gordura na fezes. Um gato apresentou episódios de vômito esporádico, cabe ressaltar que este animal possuía apetite voraz. Um gato apresentou fraqueza muscular a partir da quarta semana. A pelagem dos animais, durante 0 experimento, ficou seca, áspera e sem brilho. O comportamento geral e atividade física não se alteraram nos animais estudados. Os demais parâmetros do exame físico, dentre eles pulso femoral, temperatura e freqüência respiratória, estavam dentro dos valores normais para gatos durante o período experimental. 
Manifestações clínicas em gatos com hipertireoidismo experimental

TABELA 1 - MEDIDAS DESCRITIVAS E RESULTADO DO TESTE ESTATÍSTICO DA COMPARAÇÃO ENTRE MOMENTOS DO PARÂMETRO TT4 (nmol/L), LT4 (ng/dL), TT3 (nmol/L), EM GATOS ( $\mathrm{N}=19)$ SUBMETIDOS À TIREOTOXICOSE.

\begin{tabular}{cllllllll}
\hline & \multicolumn{7}{c}{ Momentos } \\
\cline { 2 - 8 } Medidas Descritivas & MO & M1 & M2 & M3 & M4 & M5 & M6 \\
\hline TT4 & & & & & & & \\
Mediana & 27,28 & 75,55 & 105,66 & 100,77 & 121,88 & 94,59 & 86,63 \\
Média & $36,88^{\mathrm{a}}$ & $90,03^{\mathrm{b}}$ & $106,91^{\mathrm{b}}$ & $108,16^{\mathrm{b}}$ & $116,94^{\mathrm{b}}$ & $104,17^{\mathrm{b}}$ & $104,52^{\mathrm{b}}$ \\
Desvio Padrão & 19,85 & 51,88 & 67,01 & 67,57 & 55,49 & 66,61 & 68,87 \\
LT4 & & & & & & & \\
Mediana & $3,73^{\mathrm{a}}$ & $9,90^{\mathrm{b}}$ & $13,13^{\mathrm{b}}$ & $11,84^{\mathrm{b}}$ & $13,51^{\mathrm{b}}$ & $13,64^{\mathrm{b}}$ & $9,27^{\mathrm{b}}$ \\
Média & 4,55 & 15,35 & 14,03 & 12,91 & 16,54 & 15,62 & 12,51 \\
Desvio Padrão & 3,05 & 12,42 & 8,47 & 9,03 & 13,03 & 10,5 & 7,67 \\
TT3 & & & & & & & \\
Mediana & 0,91 & 0,99 & 1,24 & 0,99 & 0,86 & 0,82 & 0,97 \\
Média & 1,38 & 1,27 & 1,21 & 1,05 & 0,88 & 0,98 & 1,08 \\
Desvio Padrão & 2,16 & 0,73 & 0,49 & 0,50 & 0,50 & 0,56 & 0,50 \\
\hline
\end{tabular}

Duas médias (ou medianas) seguidas de mesmas letras nas linhas não diferem $(P>0,05)$.

Os resultados dos achados clínicos estão dispostos na TABELA 2. A freqüência cardíaca apresentou diferença significativa de $\mathrm{M0}$ em relação aos demais; de $\mathrm{M} 1$ com relação os restantes e de M2, M3 e M4 em comparação a M5 e M6. O peso vivo apresentou decréscimo médio significativo entre os momentos estudados e correlação negativa em relação a TT4 e a LT4 em todos os momentos observados, exceto em MO.

TABELA 2 - MEDIDAS DESCRITIVAS E RESULTADO DO TESTE ESTATÍSTICO DA COMPARAÇÃO ENTRE MOMENTOS DO PARÂMETRO FREQÜÊNCIA CARDÍACA (FC), PESO (KG), CONSUMO DE ÁGUA (ML), CONSUMO DE ÁGUA POR PESO VIVO (ML/KG), CONSUMO DE RAÇÃO (G), EM GATOS (N=19) SUBMETIDOS À TIREOTOXICOSE.

\begin{tabular}{|c|c|c|c|c|c|c|c|}
\hline \multirow{2}{*}{ Medida Descritiva } & \multicolumn{7}{|c|}{ Momento } \\
\hline & $\mathrm{MO}$ & M1 & M2 & M3 & M4 & M5 & M6 \\
\hline \multicolumn{8}{|l|}{ Freqüência Cardíaca (bpm) } \\
\hline Mediana & $170^{\mathrm{a}}$ & $183^{\mathrm{b}}$ & $191^{\mathrm{c}}$ & $194^{\mathrm{C}}$ & $194^{\mathrm{c}}$ & $208.50^{d}$ & $214.50^{d}$ \\
\hline Média & 165,28 & 186,11 & 194,22 & 194,56 & 194,56 & 210 & 213,94 \\
\hline Desvio Padrão & 20,16 & 21,28 & 17,65 & 17,24 & 17,24 & 12,83 & 12,46 \\
\hline \multicolumn{8}{|l|}{ Peso Vivo (kg) } \\
\hline Mediana & 3,40 & 3,40 & 3,40 & 3,30 & 3,30 & 3,30 & 2,40 \\
\hline Média & $3,52^{d}$ & $3,45^{d}$ & $3,38^{c}$ & $3,36^{c}$ & $3,29^{b}$ & $3,24^{\mathrm{ab}}$ & $3,16^{\mathrm{a}}$ \\
\hline Desvio Padrão & 0,67 & 0,69 & 0,70 & 0,71 & 0,67 & 0,67 & 0,72 \\
\hline \multicolumn{8}{|l|}{ Consumo de Áqua $(\mathrm{mL})$} \\
\hline Mediana & $170^{\mathrm{a}}$ & $170,86^{\mathrm{a}}$ & $170,86^{\mathrm{a}}$ & $197^{\mathrm{b}}$ & $210^{c}$ & $223,43^{d}$ & $237^{\mathrm{e}}$ \\
\hline Média & 179,13 & 186,62 & 186,71 & 193,76 & 208,89 & 225,56 & 245,68 \\
\hline Desvio Padrão & 34,52 & 31,84 & 37,35 & 33,62 & 42,11 & 42,12 & 41,57 \\
\hline \multicolumn{8}{|l|}{ Consumo de Água (mL/kg) } \\
\hline Mediana & 48,05 & 48,88 & 53,85 & 56,95 & 56,95 & 65,83 & 76,66 \\
\hline Média & $53,187^{\mathrm{a}}$ & $55,540^{a}$ & $58,87^{\mathrm{ab}}$ & $60,57^{\mathrm{bc}}$ & $66,61^{\mathrm{c}}$ & $73,30^{d}$ & $82,52^{\mathrm{e}}$ \\
\hline Desvio Padrão & 16,19 & 16,60 & 19,68 & 19,05 & 21,08 & 22,99 & 25,15 \\
\hline \multicolumn{8}{|l|}{ Consumo de Ração (g) } \\
\hline Mediana & 102 & & 121 & 121 & 130 & & 149 \\
\hline Média & $103,6^{\mathrm{a}}$ & $112,5^{\mathrm{ab}}$ & $119,4^{b}$ & $124,6^{b c}$ & $133,6^{\mathrm{cd}}$ & $144,7^{\mathrm{de}}$ & $155,6^{\mathrm{e}}$ \\
\hline Desvio Padrão & 19,83 & 22,66 & 22,79 & 30,12 & 29,68 & 24,55 & 27,25 \\
\hline
\end{tabular}

Duas médias (ou medianas) seguidas de mesmas letras nas linhas não diferem $(P>0,05)$. 
O consumo de água e de ração mostraram crescimento médio ao longo dos momentos experimentais. Verificou-se correlação positiva entre consumo de água/kg/dia e TT4 em todos os momentos observados, exceto em M0 e correlação negativa entre consumo de água/ $\mathrm{kg} /$ dia e LT4 em M0 e M1 e positiva de M2 a M6. Enquanto o parâmetro consumo de ração apresentou correlação negativa com a TT4 e a LT4 entre os momentos observados.

Observou-se uma maior freqüência na micção e maior quantidade de urina livre nas caixas de excretas em todos os momentos quando comparados à M0.

\section{Discussão}

Os resultados da tireotoxicose experimental em gatos apresenta algumas particularidades importantes que diferem da literatura ou seja dos casos espontâneos. Um ponto a ser considerado é a idade dos animais (adultos jovens), visto que o hipertireoidismo felino espontâneo acomete particularmente gatos velhos (THODAY e MOONEY, 1992; PETERSON, 2004). Outro ponto é a indução da tireotoxicose em gatos sem alterações e/ou doenças concomitantes, visto que no hipertireoidismo espontâneo os animais são apresentados com doenças não tireoidianas que podem mascarar os resultados do hipertireoidismo, tanto aumentando como diminuindo os valores laboratoriais.

As coletas de sangue, para a realização do hemograma e das concentrações hormonais, foram realizadas quatro horas após a administração oral da levotiroxina sódica. A escolha deste intervalo de tempo deve-se ao pico de concentração da tiroxina em gatos após a administração oral ser de 3-4 horas (HAYS et al., 1988). A meia-vida da tiroxina por via oral em gatos é de aproximadamente 10,7 horas (HAYS et al., 1988). Entretanto não há necessidade da administração duas vezes ao dia, visto que a meia-vida não indica necessariamente a extensão ou duração da ação biológica do hormônio (PETERSON e FERGUSON, 1992).

Em gatos, o nível de produção foi estimado em $5,6 \mu \mathrm{g} / \mathrm{kg} /$ dia para a TT4 e $0,4 \mu \mathrm{g} / \mathrm{kg} / \mathrm{dia}$ para a TT3 (BROOME et al., 1987). O nível de produção dos hormônios da tireóide não é constante, havendo flutuação ao longo do dia ou entre dias (PETERSON et al., 1987) e ele também sofre influência de doenças não tireoidianas. Além disso o nível de secreção assim como o metabolismo dos hormônios tireoidianos estão aumentados no hipertireoidismo (KAPTEIN et al., 1994). Apesar destas considerações optou-se em fazer somente uma coleta por momento, sempre no mesmo horário, para minimizar as prováveis variações da secreção dos hormônios tireoidianos. Além disso, cabe ressaltar que apenas uma amostra é adequada para o diagnóstico do hipertireoidismo felino espontâneo na maioria dos casos (PETERSON et al., 1987). Em caso de dúvida repete-se o exame após algumas semanas, quando em animais com suspeita de hipertireoidismo espontâneo (PETERSON, 2004).

Os níveis séricos da média e mediana da TT4, da LT4 e da TT3 no M0, nesta pesquisa, situaram-se dentro dos valores de referência para gatos (REIMERS et al., 1981; PETERSON et al., 1983; LIU et al., 1984; TURREL et al., 1988; REFSAL et al., 1991; MOONEY et al., 1996b; FELDMAN e NELSON, 1996; PETERSON et al., 1997; 2001).

Os níveis séricos da TT4 e da LT4 encontrados do M1 ao M6 são compatíveis com os do hipertireoidismo espontâneo (REIMERS et al., 1981; REFSAL et al., 1991; MOONEY et al., 1996b; PETERSON et al., 2001). Isso demonstra que o protocolo experimental foi adequado para induzir tirotoxicose nos gatos e provocar alterações clínicas.

A razão pela qual alguns animais não apresentaram elevação nos níveis de TT4, provavelmente deve-se a problema na absorção, distribuição e biotransformação da levotiroxina sintética administrada aos gatos. Visto que os gatos não apresentavam enfermidades não tireoidianas concomitantes e, também não foi administrada qualquer droga que pudesse interferir nos valores de TT4. Outra hipótese é a desiodinação acelerada de TT4 formando uma grande quantidade de TT3, porém está hipótese é pouco provável pois o aumento do TT3 encontrado foi insignificante e, além disso, o T3 é um hormônio essencialmente intracelular (HAYS et al., 1988; 
KAPTEIN et al., 1994). Alguns gatos hipertireóideos podem apresentar variação nas concentrações hormonais, isto é, os hormônios aumentam e diminuem durante o dia (MOONEY et al., 1996b; PETERSON, 1997, 2004). Para minimizar os efeitos da flutuação poderiam ter sido realizadas outras colheitas durante o dia ou em intervalo inferior a sete dias. Porém, optamos em fazer a colheita quatro horas após a administração oral da levotiroxina sódica. A escolha deste intervalo de tempo deve-se ao pico de concentração da tiroxina em gatos após a administração oral ser de 3-4 horas e inferior a meia-vida que é de 10,7 horas (HAYS et al., 1988).

Neste estudo, somente dois gatos após o desenvolvimento da tirotoxicose, apresentaram os níveis de LT4 dentro dos valores de gatos eutiroideos. Isto já foi descrito em outros dois estudo, onde $2 \%$ (BROUSSARD et al., 1995) e $10 \%$ dos gatos com hipertireoidismo (MCLOUGHLIN et al., 1993) apresentando a LT4 dentro dos limites normais de referência. Era esperado um aumento mais significativo da LT4, pois a fração livre dos hormônios tireoidianos sofre menor interferência de fatores extratireodianos. As hipóteses ou causas prováveis são a desiodinação e a metabolização acelerada.

É importante salientar que os valores para LT4 encontrados em todos os momentos através da técnica de RIA são semelhantes aos descritos na literatura utilizando a diálise de equilíbrio, conforme já descrito anteriormente (FERGUSON et al., 1989, PETERSON et al., 1990; REFSAL et al., 1991; GRAVES e PETERSON, 1994).

Não foi observada variação entre os sete momentos quanto aos níveis séricos de TT3, fato também observado por PETERSON et al. (2001), mas são conflitantes com trabalhos anteriores (PETERSON et al.,1983; LIU et al., 1984; TURREL et al., 1988). Esta variação nos valores encontrados deve-se ao diagnóstico precoce, a utilização de técnicas diagnósticas mais sensíveis e o maior número de animais acometidos em cada trabalho. O esperado no hipertireoidismo é um aumento discreto, pois a TT3 é intracelular. A diminuição na concentração da TT3 ocorre em virtude da diminuição da conversão periférica do T4 em
T3, evento bem determinado em humanos, parece existir em gatos, mas é menos freqüente (THODAY e MOONEY, 1992). É possível que a manutenção dos níveis de TT3 inalterados seja por alteração no metabolismo ou na retroalimentação do eixo hipotálamo-hipófisetiróide.

A realização dos exames complementares foram realizados para possibilitar a identificação de possíveis fatores extra tireoidianos que pudessem interferir nos resultados ou resultados que pudessem corroborar com as explicações do desenvolvimento dos sinais clínicos. A discussão e apresentação dos resultados destes exames serão objeto de outros trabalhos.

Os sinais do sistema digestório apresentados pelos felinos, neste estudo são semelhantes aos descritos na literatura (PETERSON et al., 1983; THODAY e MOONEY, 1992; PETERSON, 1997), entretanto a sua ocorrência diferiu dos descritos por BROUSSARD et al. (1995). Estes autores relatam que a polifagia ocorre em cerca de $50 \%$ dos gatos com hipertireoidismo espontâneo, enquanto nós observamos em todos animais e sempre acompanhada de perda de peso que para estes mesmo autores é menor que $100 \%$. A perda de peso no hipertireoidismo é secundária ao aumento do metabolismo basal. O aumento do metabolismo basal por sua vez requer maior demanda calórica e conseqüentemente acarretará uma ingestão de alimentos maior (VAIL et al., 1994; PETERSON, 2004). A diarréia, o vômito e o aumento da defecação provavelmente foram fatores que também contribuíram com a perda de peso e a polifagia secundária.

O gato que apresentava episódios de vômito tinha apetite foraz, o que provavelmente contribui com o aparecimento deste sinal. Os resultados dos exames complementares neste gato nada indicaram que fosse digno de nota. O aumento na freqüência de defecação e a diarréia no hipertireoidismo são secundárias à hipermotilidade intestinal e má absorção, geralmente acompanhadas de esteatorréia macroscópica ou microscópica (PETERSON et al., 1983). Entretanto no três gatos com diarréia e nos demais que apresentavam aumento na freqüência de defecação e no volume de fezes 
não se detectou gordura no exame macroscópico ou no microscópico. Estes achados sugerem que a provável causa nestes estudo tenha sido a hipermotilidade intestinal secundária a tireotoxicidade.

A mensuração do consumo de ração e de água ficou facilitada pela manutenção dos animais em gaiolas individuais. Enquanto, 0 volume e a freqüência de defecação e a produção urinária foram estimadas pelos pesquisadores.

A tireotoxicose provocou um aumento significativo no consumo de água, acompanhada de aumento na freqüência e no volume urinário. Ressalta-se que a constatação de aumento no volume urinário foi realizada pela observação visual dos pesquisadores.

Somente $36 \%$ dos proprietários dos gatos com hipertireoidismo espontâneo relatam a PU/ PD como sinal clínico (BROUSSARD et al., 1995), estes dados diferem com os obtidos neste estudo onde $100 \%$ dos gatos apresentaram PU/PD. Os resultados sugerem que estes sinais clínicos podem passar despercebidos pelos proprietários. A correlação negativa do consumo de água/kg/ dia em relação a TT4 em todos momentos sugerem que a influência do hormônio extracelular é pequena ou ocorre de forma indireta. Já com relação a LT4 foi observada correlação positiva de M2 a M6 sugerindo que a porção livre do hormônio, isto é, aquela que exerce apta para entrar nas células e exercer a função metabólica (FELDMAN e NELSON, 1996), influência o consumo de água na tireotoxicose felina. Apesar do mecanismo das alterações renais não estarem claros sabe-se que a concentração urinária fica prejudicada devido ao aumento do fluxo sangüíneo renal, da taxa de filtração glomerular e da capacidade de secreção e reabsorção em ratos e no homem (ADAMS et al., 1997). Outra hipótese é a tireotoxicose provocar alteração no hipotálamo e esta polidipsia compulsória e secundariamente a poliúria (PETERSON, 2004), assim como a primeira hipótese também necessita de comprovação. Salienta-se que neste estudo todos os animais mantiveram a densidade urinária e as concentrações de creatinina e uréia dentro dos padrões para a espécie.
Portanto, conclui-se que a tirotoxicose não provocou nefropatia secundária nos gatos estudados diferindo de alguns animais com hipertireoidismo espontâneo (PETERSON, 2004) que apresentam nefropatia tireotóxica secundária ao aumento da taxa de filtração glomerular que leva à hiperfiltração (ADAMS et al., 1997).

A correlação negativa entre perda de peso e os hormônios tireoidianos indicam a influência deste sobre o metabolismo, pois quando maior a concentração dos hormônios maior foi a perda de peso e isto provavelmente decorre do aumento do metabolismo basal.

A fraqueza muscular que um gato desenvolveu a partir da quarta semana foi a única alteração do aparelho locomotor. A base bioquímica para a fraqueza muscular na maioria dos gatos hipertireóideos é pouca clara (PETERSON, 2004). Segundo NEMZECK et al. (1994) a redução da massa muscular provoca diminuição dos estoques de potássio e conseqüentemente a hipocalemia e a fraqueza muscular em gatos hipertireóideos. Suspeita-se que este gato tenha tido fraqueza muscular, entretanto não ocorreu diminuição do potássio e da concentração creatinaquinase que é um marcador de alterações musculares.

Durante o experimento observou-se um aumento significativo da freqüência cardíaca, entretanto somente dois gatos apresentaram taquicardia, isto é, freqüência cardíaca superior a 240 batimentos por minuto (PETERSON et al., 1983), que pode ser comprovada pela eletrocardiografia. Os valores da freqüência cardíaca são semelhantes aos descritos por FOX et al. (1999). A ausência de sinais cardiorrespiratórios graves sugerem que 0 protocolo experimental foi inadequado para provocar estas alterações secundárias à tireotoxicose.

\section{Conclusões}

A tireotoxicose experimental em gatos causou aumento da freqüência cardíaca, polifagia, polidipsia, perda de peso, aumento do volume fecal, aumento na freqüência no volume urinário. 


\section{REFERÊNCIAS}

ADAMS, W.H.; DANIEL, G.B.; LEGENDRE, A.M. Investigation of the effects of hypertyroidism on renal function in the cat. Canadian Journal Veterinary, Ottawa, v. 61, p. 53-6, 1997.

BROOME, M.R.; HAYS, M.T.; TURREL, J.M. Perifheral metabolism of thyroid hormones and iodide in healthy and hyperthyroid cats. American Journal Veterinary Research, Schaumburg, v. 48, p. 12869, 1987.

BROUSSARD, J.D.; PETERSON, M.E.; FOX, P.R. Changes in the clinical and laboratory findings in hyperthyroid cats from 1983 to 1993. Journal American Veterinary Medical Association, Schaumburg, v. 206, p. 302-5, 1995.

DIBARTOLA, S.P.; BROWN, S.A. The kidney and hyperthyroidism. In: BONAGURA, J.D. Kirk's current veterinary therapy XIII: small animal practice. Philadelphia: W.B. Saunders, 2000. p. 337-9.

FELDMAN, E.C.; NELSON, R.W. Canine and feline endocrinology and reproduction. Philadelphia. W.B. Saunders, 1996. 785 p.

FERGUSON, D.C.; PETERSON, M.E.; NACHREINER, R.F. Serum free and total iodothyronine conentrations in normal cats and cats with hyperthyroidism. Journal Veterinary Internal Medical, Lakewood, v. 3, p. 121-5,1989.

FOX, P.R.; PETERSON, M.E.; BROUSSARD, J.D. Eletrocardiographic and radiographic changes in cats with hyperthyroidim: Comparison of populations evaluated during 1992-1993 vs 1979-1982. Journal American Animal Hospital Association, Golden, v. 35, p. 27-31, 1999.

GRAVES, T.K.; PETERSON, M.E. Diagnostic tests for feline hyperthyroidism. Veterinary Clinics North American Small Animal Practice, Philadelphia, v. 4, p. 567-76, 1994.

HAYS, M.T.; BROOME, M.R.; TURREL, J.M. A multicomportamental model for iodide, thyroxine, and triiodothyronine metabolism in normal and spontaneously hyperthyroid cats. Endocrinology, Chevy Chase, v. 122, p. 2444, 1988.

KAPTEIN, E.M.; HAYS, M.T.; FERGUSON, D. Thyroid hormone metabolism: a comparative evaluation. Veterinary Clinics North American Small Animal Practice, Philadelphia, v. 24, p. 43166, 1994.
KLEIN, I. Thyroid hormone and the cardiovascular system. American Journal Medical, Alexandria, v. 86, p. 631, 1990.

LIU, S.; PETERSON, M.E.; FOX, P.R. Hypertrophic cardiomyopathy and hyperthyroidism in the cat. Journal American Veterinary Medical Association, Schaumburg, v. 185, n. 1, p. 52-7, 1984.

MCLOUGHLIN, M.A.; DiBARTOLA,; BIRCHARD, S.J. Influence of systemic nonthyroidal illness on serum concentrations of thyroxine in hyperthyroid cats. Journal American Animal Hospital Association, Golden, v. 29, p. 227-34, 1993.

MOISE, N.S.; DIETZE, N.E. Echocardiography, eletrocardiography, and radiography of cats with dilation cardioniopathy, hypertrophic cardiomypathy, and hyperthyroidism. American Journal Veterinary Research, Schaumburg, v. 47, p. 1487-94, 1986.

MOONEY, C.T.; THODAY, K.L.; DOXEY, D.L. Serum thyroxine and triidothyronine responses of hyperthyroid cats to thyrotropin. American Journal Veterinary Research, Schaumburg, v. 57, p. 987-91, 1996a.

MOONEY, C.T.; LITTLE, C.J.L.; MACRAE, A.W. Effect of illness not associated with the thyroid gland on serum total and free thyroxine concentrations in cats. Journal American Veterinary Medical Association, Schaumburg, v. 208, p. 2004-8, 1996b.

NEMZECK, J.; KRUGER, J.M.; WALSHAW, R.; HAUPTMAN, J.G. Journal American Veterinary Medical Association, Schaumburg, v. 205, p. 65-8, 1994.

PANCIERA, D.L. Cardiovascular complication of thyroid disease. In: BONAGURA, J.D. Kirk's Current Veterinary Therapy XIII: small animal practice. Philadelphia: W.B. Saunders, 2000. p. 716-9.

PETERSON, M.E.; MELIÁN, C.; NICHOLS, R. Measurement of serum concentrations of freee thyroxine, total thyroxine, and total triiodothyronine in cats with hyperthyroidism and cats with nonthyroidal disease. Journal American Veterinary Medical Association, Schaumburg, v. 218, p. 529-36, 2001.

PETERSON, M.E. Afecções hipertiroidéas. In: ETTINGER, S.J.; FELDMAN, E.C. Tratado de medicina interna veterinária. 4. ed. São Paulo: Manole, 1997. p. 2025-53.

PETERSON, M.E.; MELIÁN, C.; NICHOLS, R. Measurement of serum total thyroxine, triidothyronine, free thyroxine, and thyrotropin concentrations for diagnosis of hypothyroidism in dogs. Journal American Veterinary Medical Association, Schaumburg, v. 211, p. 1396-402, 1997. 
PETERSON, M.E.; FERGUSON, D.C. Doenças Tiroidianas. In: ETTINGER, S.J. Tratado de medicina interna veterinária. 3. ed. São Paulo: Manole, 1992. p. 1706-51.

PETERSON, M.A.; GAMBLE, D.A. Effect of nonthyroidal disease on serum thyroxine concentrations in cats: 494 cases (1988). Journal American Veterinary Medical Association, Schaumburg, v. 197, p. 1203-8, 1990.

PETERSON, M.E.; GRAVES, T.K.; GAMBLE, D.A. Triidothyronine (T3) suppression test: an aid in the diagnosis of mild hyperthyroidism in cats. Journal Veterinary Internal Medicine, Lakewood, v. 4, p. 233-8,1990.

PETERSON, M.E.; GRACES, T.K.; CAVANAGH, I. Serum thyroid hormone concentrations fluctuate in cats with hyperthyroidism. Journal Veterinary Internal Medicine, Lakewood, v. 1, p. 142-6, 1987.

PETERSON, M.E. Feline hyperthyroidism. Veterinary Clinics North American Small Animal Practice, Philadelphia, v. 14, p. 809-26, 1984.

PETERSON, M.E.; KINTZER, P.P.; E CAVANAGH, P.G.; FOX, P.R.; FERGUSON, D.C.; JOHNSON, G.F.; BECKER, D.V. Feline hyperthyroidism: Pretreatment clinical and laboratory evaluation of 131 cases. Journal American Veterinary Medical Association, Schaumburg, v. 183, p. 103-10, 1983.

PETERSON, M.E. Spontaneous hyperthyroidism in the cat. Science Proceeding ACVIM, p.108, 1979.

PETERSON, M.E. Hipertireoidismo. In: ETTINGER, S.J., FELDMAN, E.C. Tratado de medicina interna veterinária. 5. ed. Rio de Janeiro, Guanabara \& Koogan, 2004. p. 1474-95.

Recebido para publicação: 18/02/2005 Aprovado:
POLIKAR, R.; BURGER, A.G.; SCHERRER, U. The thyroid and the heart. Circulation, Boston, v. 87, p. 1435, 1993.

REFSAL., K.R.; RAYMOND, F.N.; STEIN, B.E.; CURRIGAN, C.E.; ZENDEL, A.N.; THACKER, E.L. Use of the tridothyronine suppression test for diagnosis of hyperthyroidism in ill cats that have serum concentration of iodothyronines within normal range. Journal American Veterinary Medical Association, Schaumburg, v. 199, p. 1594-601, 1991.

REIMERS, T.J.; COWAN, R.G.; DAVIDSON, H.P. Validation pf radioimmunoassaus for triidothyroxine, thyroxine, and hydrocortisone (cortisol) in canine, feline, and equine sera. American Journal Veterinary Research, Schaumburg, v. 42, p. 201621, 1981.

STREINER, D.L.; NORMAN, G.R. Bioestatistics: the bare essentials. St. Louis: Mosby - Year Book, 1994. $260 \mathrm{p}$.

THODAY, K.L.; MOONEY, C.T. Historical clinical and laboratory features of 126 hyperthyroid cats. Veterinary Record, London, v. 131, p. 257-64, 1992.

TURREL, J.M.; FELDMAN, E.C.; NELSON, R.W.; CAIN, G.R. Thyroid carcinoma causing hyperthyroidism in cats: 14 cases (1981-1986). Journal American Veterinary Medical Association, Schaumburg, v. 193, p. 359-64, 1988.

VAIL, D.M.; PANCIERA, D.L.; OGILVIE, G.K. Thyroidhormone concentrations in dogs with chronic weight loss, with special reference to cancer cachexia. Journal Veterinary Internal Medicine, Lakewood, v. 8, p. 122-7, 1994. 